\section{Formulation of Flowering Index, Morphological Relationships, and Yield Prediction System in True Garlic Aerial Seed Bulbil Production}

\author{
Deepu Mathew, ${ }^{1}$ Zakwan Ahmed, and N. Singh \\ Field Research Laboratory, Defence Research and Development Organisation, \\ Clo 56 APO, India
}

\begin{abstract}
Additional index words. Allium sativum, bolting, regression, photoperiod, vegetative propagation
\end{abstract}

\begin{abstract}
The phenomenon of flowering and aerial bulbil production in Asiatic garlic was observed under long photoperiodic conditions of Ladakh, India. Flowers were sterile and the bulbils produced on the umbel were true to type. Observations on a large number of flowering and nonflowering plants have led to the formulation of a precise flowering index (FI) in garlic. Plants with a minimum leaf number of 7, height $25 \mathrm{~cm}$, collar width $0.6 \mathrm{~cm}$, bulb diameter $3.7 \mathrm{~cm}$, bulb weight $22.5 \mathrm{~g}$, and functional leaf area of $182.4 \mathrm{~cm}^{2}$ had only shown the flowering. The flowering index formulated was a product of leaf number, plant height, functional leaf area, and bulb weight. For flowering, FI should be more than 788 , and availability of a minimum photoperiod of $\mathbf{4 0 2 0}$ hours during a growth period of 11 months was another prerequisite. Nonfulfillment of any one of the factors of flowering, although FI and photoperiod were satisfactory, led to nonflowering. Garlic aerial bulbil yield was positively correlated with leaf number, plant height, bulb weight, bulb diameter, length of flower stalk, 100 seed weight, and head diameter. Following the multiple regression model $y=-11.9-(0.00031 \times$ number of bulbils $)+(0.147 \times 100$ bulbil weight $)+(4.95 \times$ head diameter $)+(0.0460 \times$ length of flower stalk $)$, aerial bulbil yield prediction was possible at a mean accuracy of $87 \%$.
\end{abstract}

Apart from being an important condiment (Alekseeva, 1960), garlic is well known for its blood purification, anticholestrolic, and antibacterial properties since time immemorial (Tokin, 1951), and emphasis on these is growing with man's health consciousness. Allium sativum L. var. sagitatum Kuz. includes Asian, Caucasian, and Seaside ecotypes of bolting but sterile garlic (Kuznetsov, 1948). Though few seed-producing lines are isolated (Etoh, 1983; Etoh and Nakamura, 1988; Etoh et al., 1988), sterility remains to be the major constraint in its multiplication, propagation, and cultivation. The most common propagation followed in this crop continues to be vegetative using cloves, which restricts the multiplication ratio to about 10 . Nonseed formation in garlic is mainly attributed to lesser reserve material for development of fertilized ovules (Etoh et al., 1988) and competition for nutrition by simultaneously developing bulbils (Koul and Gohil, 1970). A successful strategy to restore the fertility in cultivated garlic by managing the photoperiodicity as well as temperatures during development is also formulated (Kamenetsky et al., 2004).

Ladakh, at an altitude of 9000 to $18500 \mathrm{ft}$ above mean sea level in the trans-Himalayan zone of India, is agriculturally unique with its extreme cold arid desert conditions (Table 1). Burgeoning demand had lead to the introduction

Received for publication 30 May 2005. Accepted for publication 1 Aug. 2005.

${ }^{1}$ Corresponding author; e-mail deepumathew@ movemail.com. of garlic into Ladakh in 2001. Aunique phenomenon of bolting (Fig. 1) followed by setting of aerial true to type bulbils (Fig. 2) was observed under the long (14 to $16 \mathrm{~h}$ ) photoperiods (Defence Research and Development Organisation, 2004) of Ladakh, which is highly significant in the fact that the multiplication ratio is the most important factor directing the success of any new crop, especially fornonseed-producing and lowmultiplying garlic. Within first 2 years, garlic propagation through true to type aerial bulbils offers 45 times higher multiplication rate over conventional clove method. Albeit flowering being the main factor in species allocation in this genus (Kuznetsov, 1948), studies on climatic as well as morphological requirements for the same did not receive enough attention so far. Plant and environmental factors deciding the bolting and morphological association with bulbil production and techniques for predicting the bulbil yield in Asiatic garlic are discussed.

Table 1. Meteorological observations on temperature and relative humidity in Ladakh, India (2003-04).

\begin{tabular}{lccccr}
\hline & \multicolumn{2}{c}{ Avg temp $\left({ }^{\circ} \mathrm{C}\right)$} & & \multicolumn{2}{c}{ Temp range $\left({ }^{\circ} \mathrm{C}\right)$} \\
\cline { 2 - 3 } Month & Max & Min & & Max & Min \\
\hline September & 26.3 & 13.1 & & 28.0 & 0.5 \\
October & 15.2 & -2.9 & & 18.4 & -7.0 \\
November & 11.1 & -8.0 & & 20.0 & -15.3 \\
December & 2.4 & -10.8 & & 7.0 & -17.5 \\
January & 2.4 & -12.2 & & 8.5 & -17.7 \\
February & 3.0 & -9.0 & & 9.2 & -15.3 \\
March & 6.1 & -5.5 & & 16.2 & -17.6 \\
April & 14.5 & 0.8 & 20.9 & -5.4 \\
May & 15.1 & 1.5 & & 26.2 & -3.4 \\
June & 23.9 & 10.3 & & 30.2 & 5.5 \\
July & 26.9 & 14.5 & 33.1 & 10.5 \\
August & 26.1 & 13.0 & 31.5 & 9.3 \\
\hline
\end{tabular}


remained dormant within soil under open field conditions, without any mortality during the extreme winter and snow fall from November to February, and resprouted during the last week of March. Initiation of flower heads was observed in the last week of May and the crop at this stage until bulbil maturity was used in this study. Observations on bolting behavior, plant height $(\mathrm{cm})$, bulb weight $(\mathrm{g})$, leaves per plant, functional leaf area $\left(\mathrm{cm}^{2}\right)$, bulb diameter $(\mathrm{cm})$, and collar width $(\mathrm{cm})$ were recorded at the time of $50 \%$ flowering in the population over many varieties at different altitudes in the trans-Himalayan zone. During bulbil maturity, observations on cloves per bulb, bulb diameter (cm), bulb weight $(\mathrm{g})$, head diameter $(\mathrm{cm})$, number of leaves, hundred bulbil weight ( $\mathrm{g}$ ), length of flower stalk $(\mathrm{cm})$, plant height $(\mathrm{cm})$, and bulbil yield (g) were recorded following standard morphological descriptors (Mahajan et al., 2000). For comparative photoperiodic studies, a crop was simultaneously raised under open as well as greenhouse conditions, and the photoperiod was recorded using sunshine recorder.

Observations on morphological characteristics of 600 plants, each flowering and nonflowering at $50 \%$ flowering stage, were evaluated to arrive at the minimal requisite for flowering. The level of significance of these parameters on flower induction was elucidated through correlation and path coefficient (Wright, 1921) analyses by assigning 1 for flowering and 0 for nonflowering. Parameters showing a significant positive relationship at $1 \%$ were used in the formulation of flowering index. Correlation as well as regression analyses of the data at bulbil maturity stage were used in understanding the relationship between morphological characters and bulbil yield. Bulbil yield prediction systems as a function of contributing factors were formulated following multiple regression analysis (Falconer, 1989) and were further compared at field level to choose the most efficient one.

\section{Results and Discussion}

Detailed studies on observations at $50 \%$ flowering stage have revealed the minimal morphological prerequisites for flowering in garlic. Flowering occurred only in plants with a minimum of 7 leaves. Other prerequisites for flowering in Asiatic garlic included a minimum plant height of $25.0 \mathrm{~cm}$, collar width of 0.6 $\mathrm{cm}$, bulb diameter of $3.7 \mathrm{~cm}$, bulb weight of $22.5 \mathrm{~g}$, and functional leaf area of $182.4 \mathrm{~cm}^{2}$. These predisposing factors could be assumed to be stable (Batchvarov, 1993), since, in the present-day cultivars, asexual reproduction system is evolved from an ancestral sexual reproduction system (Etoh, 1985) and characteristics such as plant height, number and size of the leaves, and bulb weight show a high level inheritance and genetic advance and are governed by polygenes (Bhojward, 1980; Sum and Park, 1986).

It was observed that plants grown under a fiber reinforced polyethylene greenhouse (FRP-gh) did not flower. Under a FRP-gh, plants were exposed for an average of 11.2
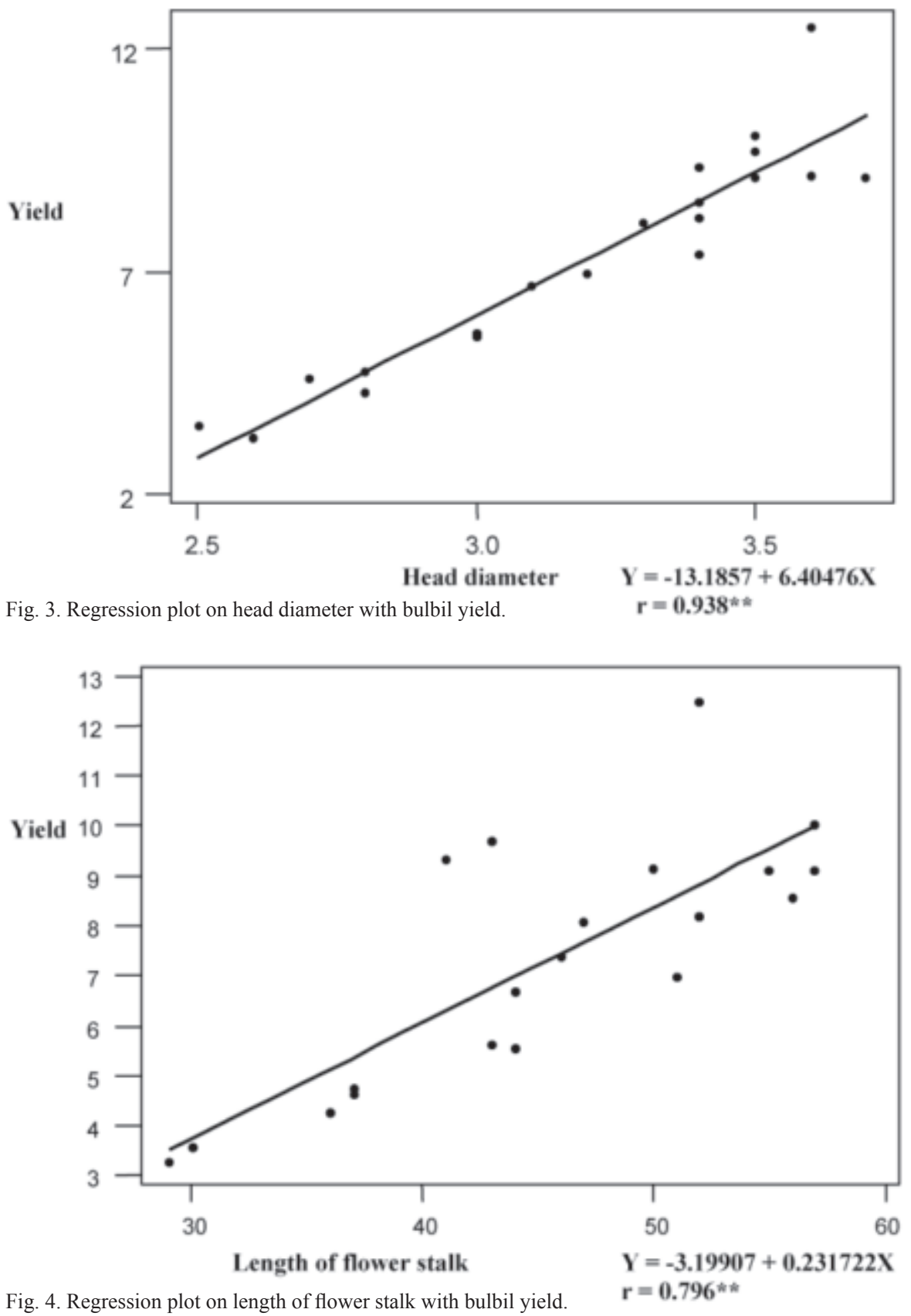

Fig. 4. Regression plot on length of flower stalk with bulbil yield.

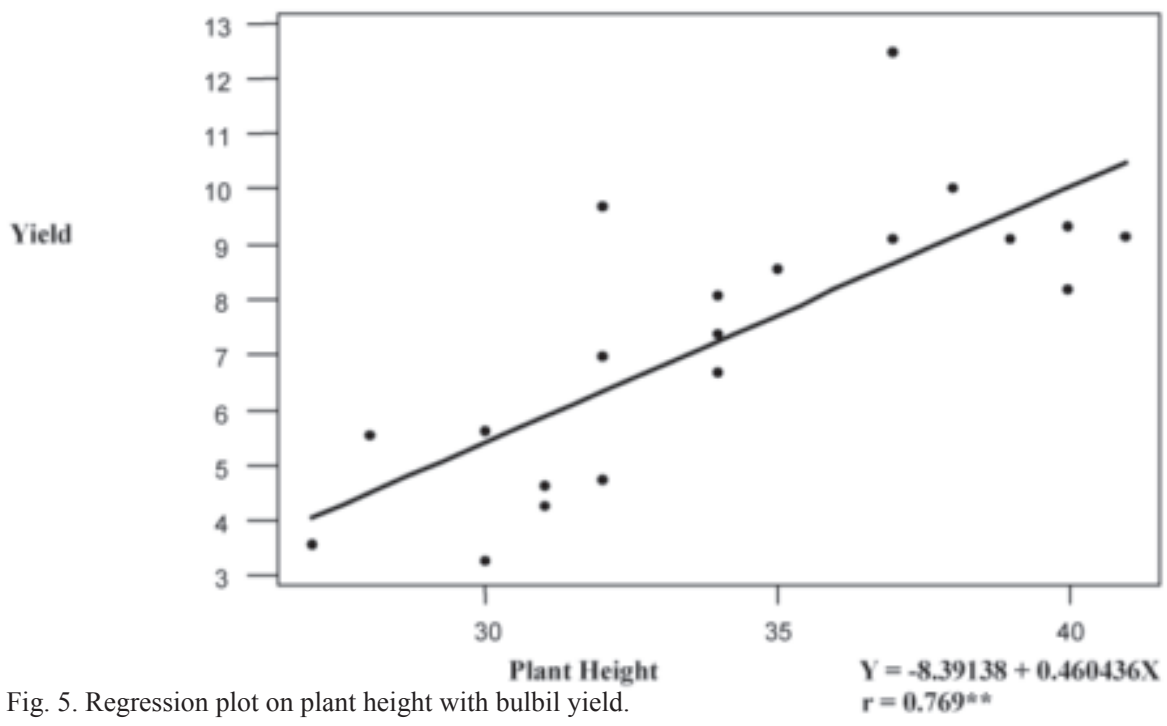


$\mathrm{h} \cdot \mathrm{d}^{-1}$; whereas, in the field, daylight duration averaged $14.9 \mathrm{~h}$ during April to July. A cumulative photoperiod of $4020 \mathrm{~h}$ during the vegetative period was needed for flower induction in Asiatic garlic in Ladakh. The long photoperiodic requirement of garlic was again evident from the nonflowering of same garlic varieties fulfilling the specified morphological requirements under northern plains of India, where the mean photoperiod was $13.3 \mathrm{~h}$ during April to July.

Character association analysis has proved the high level significant positive association of leaf number $\left(0.612^{* *}\right)$, plant height $\left(0.821^{* *}\right)$, functional leaf area $\left(0.643^{* *}\right)$, and bulb weight $\left(0.476^{* *}\right)$ with flower induction. Collar width had positive significant $\left(0.375^{*}\right)$ and bulb diameter had positive nonsignificant (0.059) association with flower induction. However, path coefficient analysis had shown these characteristics to be direct functions of bulb weight and their prerequisites were fulfilled with the same. Thus, no plant had shown nonflowering because the collar width was $<0.6$ $\mathrm{cm}$ or bulb diameter was $<3.7 \mathrm{~cm}$, but were automatically met in flowering plants. Based on these results, flowering index (FI) was formulated as a product of leaf number, plant height, functional leaf area, and bulb weight. For flowering in Asiatic garlic, FI should be $>788$. Satisfying FI along with the specified morphological requirements and photoperiod had lead to flowering in garlic. Nonfulfillment of any one factor, even though FI is satisfactory, resulted in nonflowering.

The association of characters such as bulb weight, number of cloves per bulb, plant height, length of flower stalk, number of bulbils per head, 100 bulbil weight, leaf number, head diameter and bulb diameter with aerial bulbil yield was revealed from correlation and regression studies at complete bulbil maturity. Head diameter had shown maximum positive significant correlation $\left(r=0.938^{* *}\right)$ with bulbil yield (Fig. 3). Length of flower stalk $\left(0.796^{* *}\right)$, plant height $\left(0.769^{* *}\right)$, and number of leaves per plant $\left(0.735^{* *}\right)$ also had shown high level significant positive correlation with bulbilyield (Figs. 4, 5, and 6, respectively). Bulb weight $\left(0.619^{* *}\right), 100$ seed weight $\left(0.494^{*}\right)$ and bulb diameter $\left(0.492^{*}\right)$ also had a positive significant relation with bulbil yield (Figs. 7, 8, and 9, respectively). Plant height was the only factor which has significantly $\left(0.455^{* *}\right)$ increased the individual bulbil weight.

Prediction of character expression using the regression and correlation analysis of characters with positive and highly significant correlation is well demonstrated (Falconer, 1989). Garlic aerial bulbil yield was successfully predicted from morphological observations at complete bulbil maturity. Among the various multiple-regression models compared at field level, $\mathrm{y}=-11.9-0.00031 \mathrm{C}_{1}+0.147$ $\mathrm{C}_{2}+4.95 \mathrm{C}_{3}+0.0460 \mathrm{C}_{4}$, where, $\mathrm{y}$ - bulbil yield/head (g), $\mathrm{C}_{1}$ - number of bulbils/ head, $\mathrm{C}_{2}$ - hundred bulbil weight $(\mathrm{g}), \mathrm{C}_{3}$ - head diameter (cm), and $\mathrm{C}_{4}$ - length of flower stalk ( $\left.\mathrm{cm}\right)$, was found to be the most efficient (87\%).

Reproduction through aerial bulbils, although limited to Allium sativum var. sagitatum
Kuz., is very good alternative in mass clonal multiplication, and bulbils act as substitutes for true garlic seeds (Batchvarov, 1966). In garlic, toward the end of the vegetative period, the last two leaves turn fertile; i.e., at the base of the leaves, cloves and flower stem are formed (Batchvarov, 1994). Under Ladakh conditions, it was found that bulbils of pea size planted in September, before the onset of severe winter, formed normal plants with one or two cloved bulbs weighing a maximum of $28.6 \mathrm{~g}$, which in turn produced normal plants bearing many cloves and bulbils in the second year of culture. Since a single normal clove of bolting garlic will multiply into about 10 cloves and 400 bulbils in a year and by the end of the second year, 4500 plants, including 500 normal cloves (400 bulbils of first year +10 cloves of first year multiplied to 100) and 4000 bulbils (400 each from 10 cloves of first year). Thus, the multiplication ratio over nonbolting cultivars is about 45 times. The multiplication rate of bolting garlic projected for 11 years of continuous culture was $y=-3.4 \mathrm{e}^{13}+37.3160 \mathrm{X}$
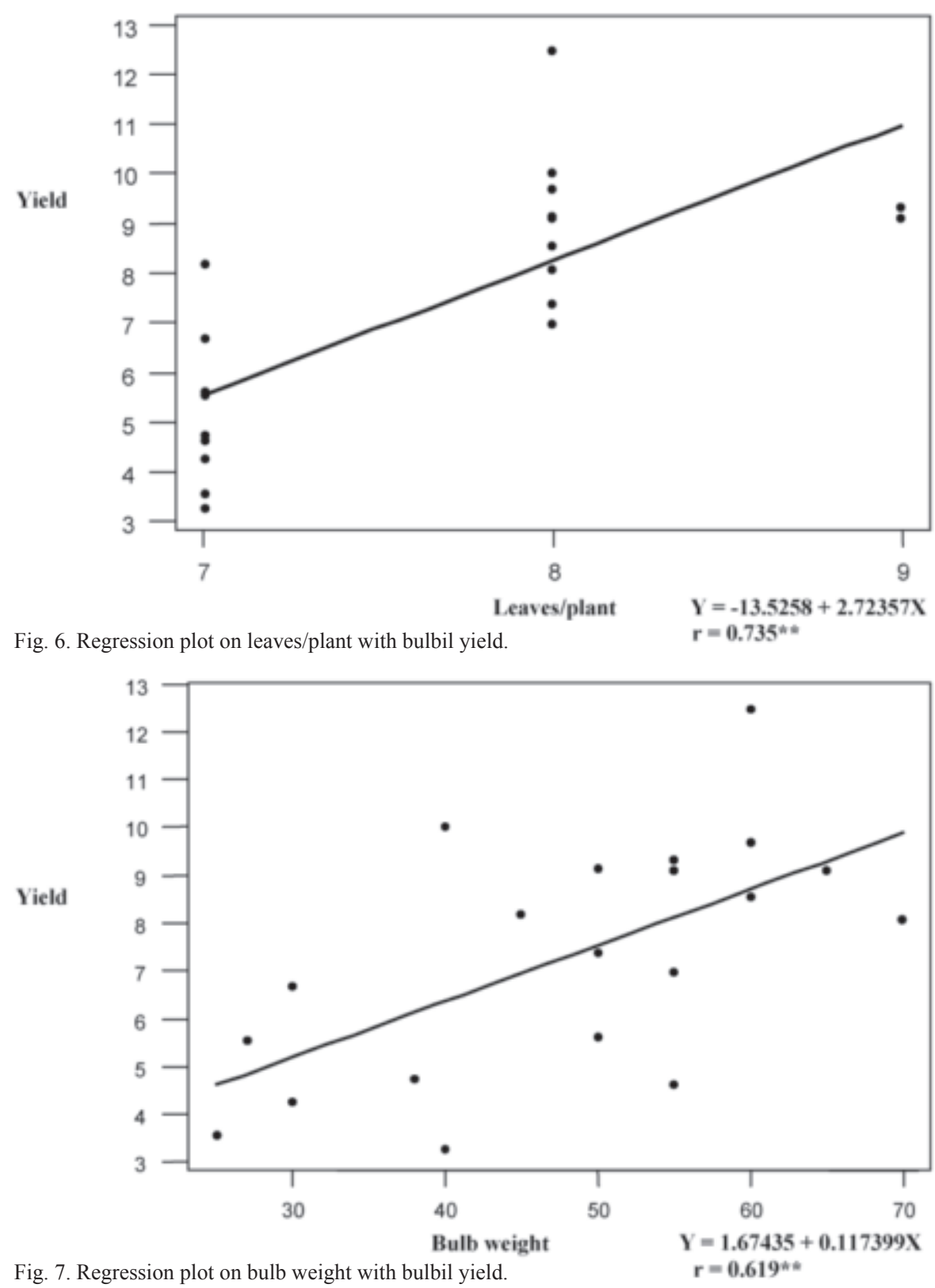

where, $y=$ the number of plants obtained after a specific generation and $X=$ the number of plants (including cloves and bulbils) used for planting. It was also observed that bolting garlic multiply by a factor of 10.73 during even years and 37.29 during odd years, since during even years bulbils develop into cloves and during odd years both multiply through bulbils as well as cloves. From an economic perspective, after 2 years of culture, yield realized through bulbils was 3 times higher than conventional system. However, propagation through vegetative means only is not advisable in any crop, since this results in a higher level of heterogeneity within a homozygous system (Chaudhary and Mehla, 1997), which is not desirable in terms of abiotic and biotic stress resistance (Knights, 1991) and manifestation of hybrid vigour (Swaroop, 1886). Temperature, relative humidity, daylength, light intensity, and their combinations can induce frequent changes in the genome of garlic (Batchvarov, 1993). Subzero temperatures, prevalent under Ladakh conditions and under which aerial bulbils are

HortScience Vol. 40(7) December 2005 


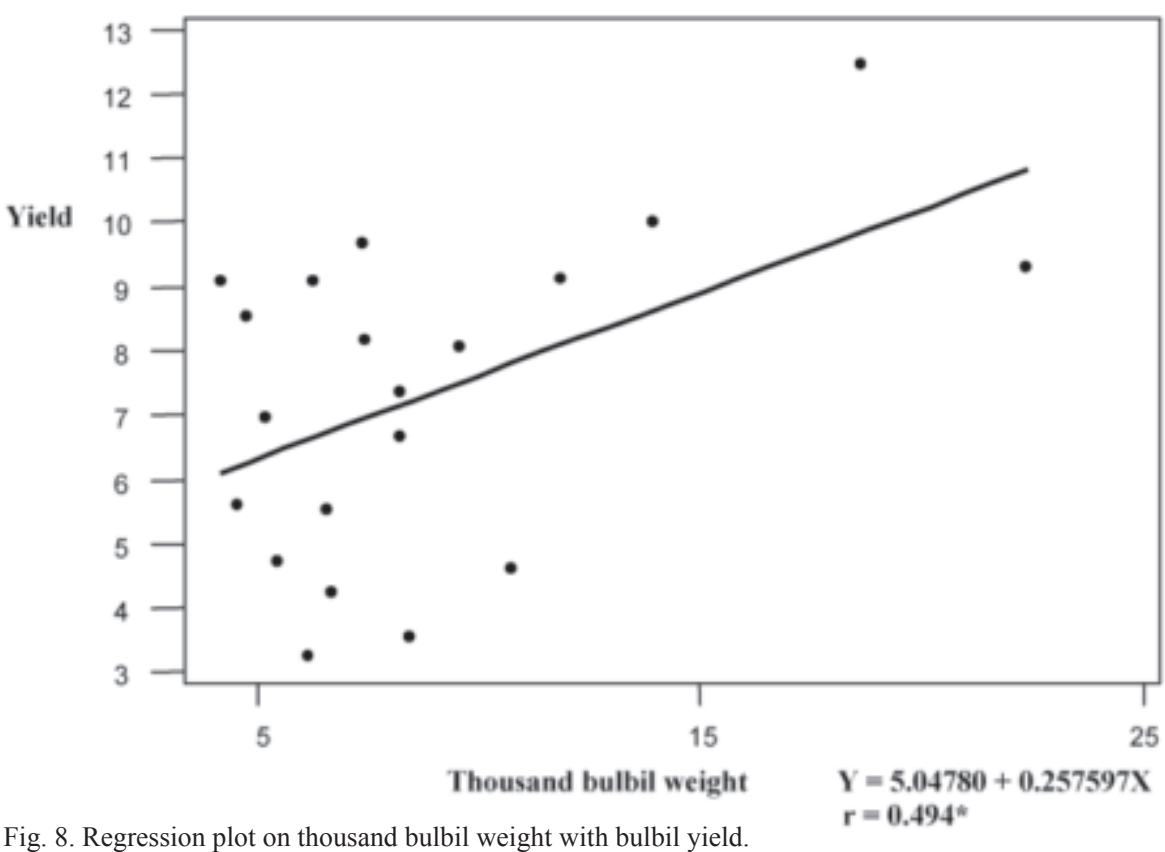

Fig. 8. Regression plot on thousand bulbil weight with bulbil yield.

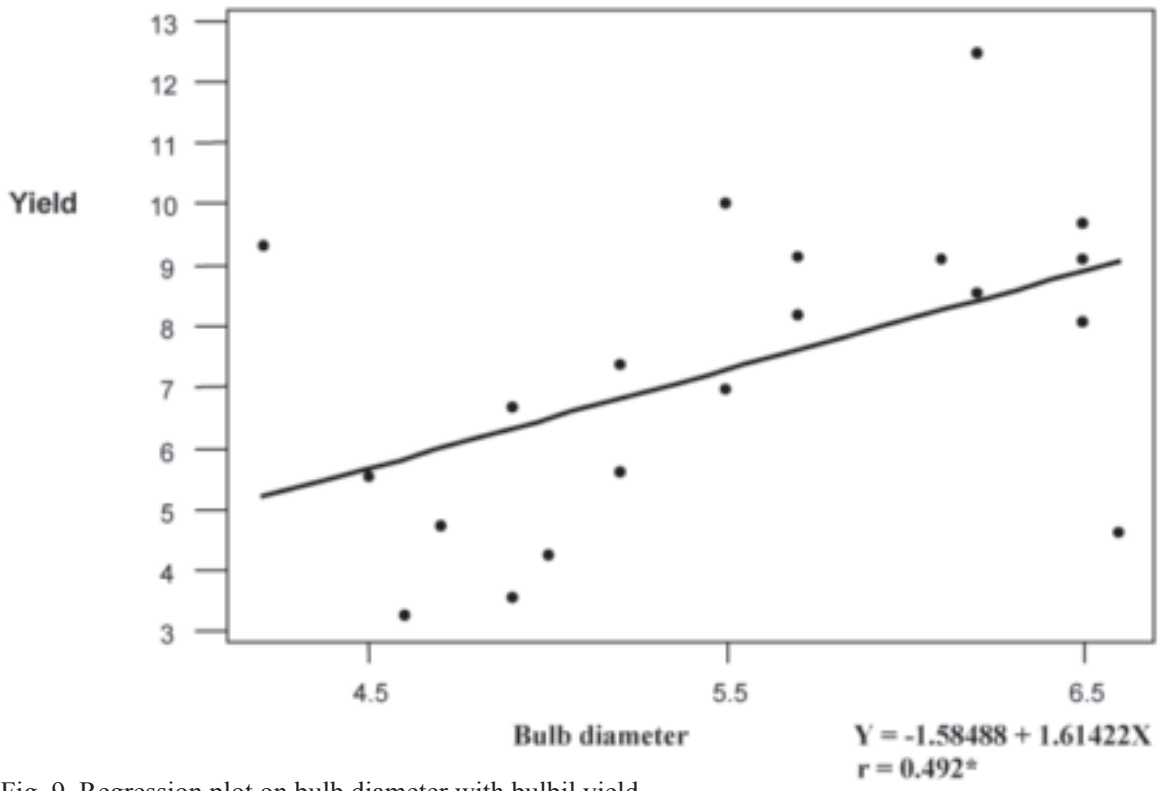

Fig. 9. Regression plot on bulb diameter with bulbil yield.

more exposed than underground bulbs, open a new area of selection breeding.

Another advantage of propagation using true-to-type aerial bulbils is that the bulbils are biologically younger and free from nematode infection and other diseases - mosaic virus in particular (Etoh and Nakamura, 1988). In garlic vegetative propagation of any kind, regardless of the site from which the propagule is selected, all the features of the parents are transferred to the next generation and no deviation from the karyotype has been found among the plantlets (Chang and Park, 1980). In this context, information on morphological gamon Press, Oxford, U.K.

Batchvarov, S. 1966. Garlic. Zemizdat, Sofia.

Bhojward, S. 1980. In vitro propagation of garlic by shoot proliferation. Sci. Hort. 13:47.

Chang, J.I. and Y.B. Park. 1980. Studies on the improvement of garlic cultivation in Cheju. 2. Effect of cold treatment of garlic cloves and the transplanted seedlings on yield. J. Kor. Soc. Hort. Sci. 21:1.

Chaudhary, B.S. and A.S. Mehla. 1997. Problems and perspectives of sugarcane, p. 169-176. In: R.L. Kapoor and M.L. Saini (eds.). Plantbreeding and crop improvement. vol. 1. CBS Publ. and Distributors, New Delhi, India.

Defence Research and Development Organisation. 2004. Annual report. Field Res. Lab. (DRDO), India.

Etoh, T. and N. Nakamura. 1988. Comparison of the peroxidase isozyme between fertile and sterile clones of garlic, p. 115. 4th EUCARPIA Allium Symp. 6-9 Sept.

Etoh, T. 1983. Accomplishment of microsporogenesis in a garlic clone. Mem. Fac. Agr. Kagoshima Univ. 19:55-63.

Etoh, T. 1985. Studies on sterility in garlic, Allium sativum L. Mem. Fac. Agr. Kagoshima Univ. 21:77-132.

Etoh, T, Y. Noma, and Y. Nishitarumizu. 1988. Seed productivity and germinability of various garlic clonescollected in Soviet central Asia. Mem. Fac. Agr. Kagoshima Univ. 24:129-139.

Falconer. 1989. Introduction to quantitative genetics. 3rd ed. Longman, New York.

Kamenetsky, R, I.L. Shafir, H. Zemah, A. Barzilay, and H.D. Rabinowitch. 2004. Environmental control of garlic growth and florogenesis. J. Amer. Soc. Hort. Sci. 129:144-151.

Knights, E.J. 1991. Introgression in crop improvement, p. 243-253. In: A.K. Mandal, P.K. Ganguly, and S.P. Banerjee (eds.). Advances in plant breeding. vol 2. CBS Publ. and Distributors, New Delhi, India.

Koul, A.K. and R.N. Gohil. 1970. Causes averting sexual reproduction in Allium sativum Linn. Cytol. 35:197-202.

Kuznetsov, A.V. 1948. Agrobiological studies of garlic. Phg, Krasnodar. (cited in Batchvarov, 1993). Garlic (Allium sativum L.), p. 15-27. In: G. Kalloo and B.O. Bergh (eds.). Genetic improvement of vegetable crops. Pergamon Press, Oxford, U.K.

Mahajan, R.K, R.L. Sapra, U. Srivastava, M. Singh, and G. D. Sharma. 2000. Minimal descriptors (for characterization and evaluation) of agrihorticultural crops. Part I. Natl. Bur. Plant Genet. Resour., New Delhi.

Singh, N, B. Raut, and N. Kumar. 2003. Cultural tips for vegetable production in Ladakh. Field Res. Lab. (DRDO), India.

Sum, S.K. and N.G. Park. 1986. Studies on the anther culture of garlic (A. sativum L.). callus formation and plant regeneration. J. Kor. Soc. Hort. Sci. 37:89.

Swaroop, V. 1986. Breeding procedures for cross pollinated vegetables. Indian Council Agr. Res., New Delhi, India.

Tokin, B.P. 1951. Phytonzides. Acad. Med. Nauk. Moscow 170:196.

Wright, S. 1921. Correlation and causation. J. Agr. Res. 20:257-287. 